\title{
Pengaruh latihan fisik akut terhadap saturasi oksigen pada pemain basket mahasiswa Fakultas Kedokteran Unsrat
}

\author{
${ }^{1}$ Ryan H. Simanjuntak \\ ${ }^{2}$ Joice N. A. Engka \\ ${ }^{2}$ Sylvia R. Marunduh
}

\author{
${ }^{1}$ Kandidat Skripsi Kedokteran Universitas Sam Ratulangi Manado \\ ${ }^{2}$ Bagian Fisiologi Fakultas Kedokteran Universitas Sam Ratulangi Manado \\ Email : ryan_12039@yahoo.com
}

\begin{abstract}
Physical exercise is a planned regular and repeated activities in a certain intensity to improve health. Based on duration, there are two kinds of physical exercise. Physical exercise with shorter amount of time is called acute physical exercise. While physical exercise with longer amount of time is called chronic physical exercise. Physical exercise will make some changes in the body, such as blood oxygen levels. Some studies showed the influence of physical exercise on oxygen saturation but some studies had the opposite result. Therefore, this study was carried out to investigate the effect of acute physical exercise on oxygen saturation. This study was a field experimental with pre-post one group test design that was conducted to 32 Medical Faculty student basketball players of Sam Ratulangi University. Each subject had to play basketball for 20 minutes. Value of oxygen saturation was checked using pulse oximeter before exercise and immediately after exercise. Case analysis use paired samples $\mathrm{T}$ test. This study has found an increase on oxygen saturation after the acute physical exercise $(\mathrm{p}=0,041 ; \mathrm{p}<0,05)$.
\end{abstract}

Keywords: acute physical exercise, oxygen saturation

\begin{abstract}
Abstrak: Latihan fisik adalah aktivitas yang dilakukan secara terencana, teratur dan berulang ulang dalam intensitas tertentu untuk meningkatkan taraf kesehatan. Berdasarkan durasinya, ada dua jenis latihan fisik. Latihan fisik dengan durasi singkat disebut latihan fisik akut. Sedangkan latihan fisik dengan durasi yang lama disebut latihan fisik kronik. Latihan fisik akan menyebabkan beberapa perubahan dalam tubuh, seperti kadar oksigen dalam darah. Beberapa penelitian menunjukkan adanya pengaruh latihan fisik terhadap terhadap saturasi, namun beberapa penelitian menunjukkan hasil sebaliknya. Oleh karena itu penelitian ini bertujuan untuk mengetahui pengaruh antara latihan fisik akut terhadap saturasi oksigen. Penelitian ini merupakan suatu penelitian eksperimental lapangan dengan rancangan pre-post one group test yang dilakukan terhadap 32 orang mahasiswa pemain basket Fakultas Kedokteran Universitas Sam Ratulangi. Responden diberi perlakuan berupa olahraga basket selama 20 menit. Nilai saturasi diperiksa menggunakan alat pulse oksimetri, diperiksa sesaat sebelum latihan dan sesaat sesudah latihan. Analisis hasil penelitian menggunakan uji $\mathrm{T}$ berpasangan. Hasil penelitian ini menunjukkan adanya peningkatan pada nilai saturasi oksigen setelah latihan fisik akut $(\mathrm{p}=0,041 ; \mathrm{p}<0,05)$.
\end{abstract}

Kata kunci: latihan fisik akut, saturasi oksigen

Latihan fisik merupakan kegiatan yang dilakukan seseorang untuk meningkatkan dan memelihara kebugaran tubuh, serta dianjurkan pada setiap individu agar terhindar dari berbagai macam penyakit. Berdasarkan data WHO, orang dengan latihan fisik tidak adekuat, akan terjadi peningkatan pada semua penyebab 
kematian sebesar 20\% - 30\%, dibandingkan dengan orang yang latihan fisik minimal 150 menit intensitas sedang per minggu. Pada tahun 2010, 23\% orang dewasa 18 tahun keatas, latihan fisiknya tidak adekuat. Prevalensi tertinggi ada pada daerah Amerika (32\%) dan terendah pada daerah Asia Tenggara (15\%). Sebuah studi mengatakan bahwa dengan meningkatkan latihan fisik sebanyak 10\%, dapat mencegah kematian sebanyak 533.000 jiwa/tahun, jika ditingkatkan sebanyak 25\% maka 1.300.000 kematian dapat dicegah. ${ }^{1-4}$

Berdasarkan penggunaan akan oksigen latihan fisik terbagi 2 yaitu latihan aerobik dan anaerobik. Latihan fisik aerobik memerlukan oksigen untuk pembentukan energi sedangkan latihan fisik anaerobik tidak memerlukan oksigen untuk pembentukan energi. Latihan fisik juga dapat dibedakan berdasarkan durasinya, yaitu latihan fisik akut dan kronis. Latihan fisik akut adalah latihan fisik yang dilakukan dalam durasi singkat maksimal 30 menit, sedangkan latihan fisik kronis adalah latihan fisik dengan durasi yang lebih lama minimal 30 menit. ${ }^{5-9}$

Latihan fisik akan menyebabkan beberapa perubahan dalam tubuh, seperti kadar oksigen dalam darah. Normalnya dalam darah terdapat cadangan oksigen. Saat melakukan latihan fisik tubuh memerlukan oksigen dalam jumlah yang besar untuk memenuhi kebutuhan akan energi. Oksigen akan diambil oleh darah melalui paru paru dan berikatan dengan hemoglobin. Jika kadar oksigen dalam darah menurun melewati batas normal akan sangan berbahaya bagi tubuh karena dapat menyebabkan pingsan sampai kematian., 12

Penelitian sebelumnnya yang dilakukan oleh Sinambela pada penderita PPOK stabil di RSU Adam Malik Medan yang diberikan latihan fisik, tidak menunjukkan adanya perubahan yang signifikan pada nilai saturasi oksigen pada derajat berat-sangat berat namun dijumpai perubahan yang signifikan pada kelompok derajat ringan-sedang. ${ }^{13}$

Penelitian serupa dilakukan oleh
Wicaksono terhadap unit bola basket mahasiswa Universitas Muhammadiyah Surakarta dengan cara memberikan latihan aerobik berupa lari selama 20 menit pada kelompok perlakukan. Dijumpai adanya perubahan yang signifikan pada nilai saturasi oksigen sebelum dan sesudah latihan dengan selisih sebesar $1.88 \%$ yang membuktikan adanya pengaruh latihan fisik terhadap peningkatan nilai saturasi oksigen. $^{14}$

\section{METODE PENELITIAN}

Jenis penelitian yang dilakukan bersifat eksperimental lapangan dengan rancangan penelitian one group pre-post test. Penelitian ini dilaksanakan pada bulan Oktober 2015 sampai bulan Desember 2015. Tempat penelitian di Kampus FK Unsrat yang bertempat di Kampus FK Malalayang. Populasi penelitian ini adalah mahasiswa FK Unsrat. Sampel penelitian diambil dari sebagian populasi yang sesuai dengan kriteria inklusi, yaitu pemain basket berusia 16-22 tahun dan bersedia menjadi responden dan menandatangani informed consent.

Definisi operasional latihan fisik akut adalah latihan fisik dengan durasi yang singkat tidak lebih dari 30 menit. Saturasi oksigen adalah presentasi hemoglobin yang berikatan dengan oksigen dalam darah.

\section{HASIL PENELITIAN}

Sampel diambil dari sebagian populasi yang telah memenuhi kriteria inklusi dan diperoleh sebanyak 32 responden. Berikut ini akan diuraikan hasil penelitian dalam bentuk tabulasi dan penjelasan.

\section{Distribusi rerata nilai saturasi oksigen sebelum dan sesudah latihan fisik berdasarkan jenis kelamin}

Responden dengan jenis kelamin laki laki sebanyak 26 orang (81,3\%) dengan rerata nilai saturasi oksigen sebelum latihan 97,42\% dan meningkat sesudah latihan sebesar 97,85\%. Responden dengan jenis kelamin perempuan berjumlah lebih sedikit, yakni 6 orang (18,8\%) dengan nilan rerata sebelum latihan $97,50 \%$ dan 
meningkat setelah latihan sebesar 98,17\%. Secara keseluruhan nilai rerata saturasi oksigen sebelum latihan adalah 97,44\% dan meningkat setelah latihan menjadi 97,91\%.

Tabel 1. Distribusi nilai saturasi oksigen berdasarkan jenis kelamin

\begin{tabular}{|c|c|c|c|c|}
\hline \multirow[t]{2}{*}{$\begin{array}{c}\text { Jenis } \\
\text { Kelamin }\end{array}$} & \multirow[t]{2}{*}{$\mathrm{F}$} & \multirow[t]{2}{*}{ P (\%) } & \multicolumn{2}{|c|}{$\begin{array}{l}\text { Rerata nilai } \\
\text { saturasi } \\
\text { oksigen (\%) }\end{array}$} \\
\hline & & & $\begin{array}{l}\text { Pre } \\
0742\end{array}$ & $\begin{array}{l}\text { Post } \\
9785\end{array}$ \\
\hline $\begin{array}{l}\text { Laki laki } \\
\text { Perempuan }\end{array}$ & $\begin{array}{c}26 \\
6\end{array}$ & $\begin{array}{l}81,3 \\
18,8\end{array}$ & $\begin{array}{l}97,42 \\
97,50\end{array}$ & $\begin{array}{l}97,85 \\
98,17\end{array}$ \\
\hline Total & 32 & 100 & 97,44 & 97,91 \\
\hline
\end{tabular}

\section{Hasil uji statistik uji $\mathrm{T}$ berpasangan}

Berdasarkan uji statistik yaitu uji T berpasangan, didapatkan nilai $\mathrm{p}=0,041$ $(<0,05)$ maka hipotesis diterima yaitu terdapat peningkatan nilai saturasi oksigen sesudah diberikan perlakuan berupa latihan fisik olahraga basket.

Tabel 2. Hasil uji T berpasangan nilai saturasi oksigen sebelum dan sesudah latihan fisik

\begin{tabular}{ccc}
\hline Test & Hasil & Keputusan \\
\hline $\begin{array}{c}\text { Uji T } \\
\text { berpasangan }\end{array}$ & 0,041 & $\mathrm{H}_{1}$ Diterima \\
\hline
\end{tabular}

\section{BAHASAN}

Bedasarkan data tabel 1 di atas pada jenis kelamin laki laki dan perempuan didapatkan nilai saturasi oksigen pada rentang yang normal. Nilai normal saturasi oksigen berkisar antara 95\% - 100\%. Hal ini menunjukkan pada rentang usia 17 - 21 tahun kemampuan hemoglobin mengikat oksigen masih normal. Pada usia lanjut, semakin tua usia maka kemampuan hemoglobin mengikat oksigen akan semakin menurun. ${ }^{12,13,15-17}$

Rerata nilai saturasi oksigen secara keseluruhan berdasarkan tabel 2, sebelum diberikan latihan fisik adalah 97,44\% dan meningkat sesudah diberikan latihan fisik menjadi 97,91\%. Hal ini dimungkinkan karena 4 menit setelah latihan fisik dimulai akan terjadi peningkatan ambilan oksigen oleh paru - paru sebesar 15 kali dari normalnya dan menurun sedikit demi sedikit sampai 40 menit setelah latihan fisik. Selain itu akan terjadi peningkatan aliran darah sampai 25 kali lipat selama latihan. Dengan meningkatnya ventilasi dan aliran darah, akan semakin banyak oksigen yang berdifusi ke kapiler paru dan berikatan dengan hemoglobin. Berdasarkan hal tersebut di atas, maka tubuh dapat mempertahankan kadar oksigen dalam darah agar tidak menurun selama latihan fisik, dan nilai saturasi oksigen setelah latihan fisik akan tetap atau mengalami peningkatan. $^{10,11,18,19}$

Pada penelitian yang dilakukan Sinambela terhadap 12 orang penderita PPOK stabil di RSU Adan Malik Medan dengan cara memberikan latihan fisik selama 8 minggu. Hasil penelitian tidak dijumpai perbedaan yang bermakna nilai saturasi oksigen pada derajat berat-sangat berat namun dijumpai perbedaan yang bermakna pada kelompok derajat ringansedang. ${ }^{13}$

Penelitian serupa dilakukan oleh Wicaksono pada tahun 2015 terhadap unit bola basket mahasiswa Universitas Muhammadiyah Surakarta dengan cara memberikan latihan aerobik lari selama 20 menit. Pengukuran nilai saturasi menggunakan alat oksimetri dan analisis hasil menggunakan uji komparatis Wilcoxon Signed Ranks Test dan uji Chi Square. Hasil penelitian didapatkan rerata sebelum latihan adalah 96,06\% dan meningkat setelah latihan menjadi 97,94\%. Berdasarkan uji beda pengaruh diperoleh nilai $\mathrm{p}=0,000$ yang membuktikan adanya pengaruh latihan aerobik terhadap peningkatan nilai saturasi oksigen. ${ }^{14}$

Latihan fisik dapat bermanfaat bagi tubuh, terlepas dari pengaruhnya terhadap faktor - faktor resiko yang lain. Seseorang yang rajin latihan fisik dapat mengerjakan suatu pekerjaan otot dengan lebih efisien dibanding dengan yang jarang melakukan latihan fisik. Seseorang dengan latihan fisik rutin dapat meningkatkan kemampuan kardiovaskuler. Latihan fisik rutin juga dapat meningkatkan kapasitas vital paru 
dan meningkatkan ambilan oksigen oleh paru dan oksigen yang dipergunakan tubuh akan cepat tergantikan. Dengan begitu latihan fisik secara rutin nilai saturasi oksigennya akan meningkat atau tetap setelah selesai melakukan latihan fisik. Hal ini dapat membantu tubuh untuk latihan fisik yang lebih lama dan optimal, karena jika pasokan oksigen ke otot mencukupi, kebutuhan akan energi akan lebih mudah terpenuhi. ${ }^{3,10,11 \text {, }}$

\section{SIMPULAN DAN SARAN}

Berdasarkan hasil penelitian yang dilakukan, didapatkan bahwa terdapat peningkatan nilai saturasi oksigen yang signifikan dengan nilai $\mathrm{p}=0,041$ setelah melakukan latihan fisik akut.

\section{DAFTAR PUSTAKA}

1. Matindas WR. Pengaruh latihan fisik akut terhadap kadar gula darah mahasiswa Fakultas Kedokteran Universitas Sam Ratulangi Manado. Jurnal Biomedik [serial on the internet]. 2013 [cited 2015 Des 22]; 5. Available from: http://ejournal.unsrat.ac.id/index.php/bi omedik/article/view/2612

2. World Health Organization. Prevelance of insufficient physical activity [homepage on the internet]. 2015 [cited 2015 Okt 7]. Available from: http://www.who.int/gho/ncd/risk_fa ctors/physical_activity_text/en/

3. Nat Geo Indonesia. 8 manfaat latihan fisik bagi kesehatan [homepage on the internet]. 2014 Mar 2 [cited 2015 Sep 21]. Available from: http://nationalgeographic.co.id/berit a/2014/03/8-manfaat-latihan-fisikbagi-kesehatan.

4. Park A. Lack of Exercise as Deadly as Smoking [homepage on the internet]. 2012 Jul 18 [cited 2015 oct 03]. Avaible from: http://healthland.time.com/2012/07/18/1 ack-of-exercise-as-deadly-as-smokingstudy-finds/

5. MedicineNet. Aerobic exercise [homepage on the internet]. 2015 Jan 26 [cited 2015 Okt 2]. Available from: http://www.medicinenet.com/aerob ic_exercise/page3.htm

6. Departement of Health, The Goverment of the Hong Kong Special Administrative Region. Classification of physical activity and level of intensity [homepage on the internet]. 2011 [cited 2015 Sep 27]. Available from: http://www.change4health.gov.hk/e n/physical_activity/facts/classificati on/index.html

7. USU Institutional Repository. ChapterII.pdf [serial online]. 2013 [cited 2015 Des 29]. Available from: http://repository.usu.ac.id/bitstream /123456789/31340/4/Chapter\%20II.pdf

8. The Community. Acute exercise [homepage on the internet]. [cited 2016 Jan 12]. Available from: http://www.answers.com/Q/What_i s_acute_exercise.

9. Nicolelectric, Tangerine, Drizzler. Chronic exercise [homepage on the internet]. 2011 Jan 11 [cited 2016 Jan 12]. Available from: http://www.acne.org/messageboard /topic/286900-chronic-exercise/

10. Guyton AC, Hall JE. Fisiologi kedokteran (Edisi ke-11). Jakarta: EGC; 2006. h. 532, 545-7, 111121.

11. West JB. Respiratory physiology: the essentials (8th ed). California: Lippincott Williams \& Wilkins; 2008. h. 76-7.

12. Schutz S. Oxygen saturation monitoring by pulse oximetry (4th ed). Amerika: AACN procedure manual for critical care; 2001.

13. Sinambela AH, Tarigan AP, Pandia P. Pengaruh latihan fisik terhadap saturasi oksigen pada penderita Penyakit Paru Obstruktif Kronik Stabil. JRI [serial online]. 2015;35. Available from: http://jurnalrespirologi.org/wpcontent/uploads/2015/08/JRI-Jul2015-35-3-167-71.pdf

14. Wicaksono S. Pengaruh latihan aerobik terhadap peningkatan saturasi oksigen pada pemain bola basket unit bola basket Universitas Muhammadiyah Surakarta [serial online]. 2015. Available from: http://eprints.ums.ac.id/35686/1/Na 
skah\%20publikasi.pdf.

15. Ward JPT, Clarke RW, Linden RWA. At a glance fisiologi. Jakarta:

Erlangga; 2009. h. 57.

16. Widjanegara IG. Senam asma mengurangi kekambuhan dan meningkatkan saturasi oksigen pada penderita asma di poliklinik paru rumah sakit umum daerah Wangaya Denpasar [tesis]. Denpasar: Universitas Udayana; 2014.

17. Triwijayanti A. Studi deskriptif pemberian oksigen dengan head box terhadap peningkatan saturasi oksigen pada neonatus di ruang perinatologi rumah sakit islam kendal [serial online]. 2014. Available from:

http://digilib.unimus.ac.id/files/disk1/15 2/jtptunimus-gdl-anatriwija-7592-3babiis-a.pdf.

18. Yuliastrid D. Peningkatan ventilasi paru selama latihan fisik dan peningkatan VO2Max akibat latihan fisik. Ilmu Keolahragaan [serial on the internet]. 2014 [cited 2015 Des 23];6 (2). Available from: http://ejournal.unesa.ac.id/index.php/jur nal_ikor/article/view/9857/129 56
19. Rozi KW. The Comparation Of Lung Vital Capacity In Various Sport Athlete. Faculty of Medicine, Lampung University. 2015;4:2

20. World Health Organization. Physical activity [homepage on the internet]. 2010 [cited 2015 Sep 27]. Available from:

http://www.who.int/topics/physical _activity/en/

21. Trigonal Media. Pengertian latihan menurut para ahli [homepage on the internet]. 2014 Nov 29 [cited 2015 Sep 26]. Available from: http://www.trigonalmedia.com/201 4/11/pengertian-latihan-menurutpara-ahli.html?m=1

22. Razali. Keterampilan bermain bola basket. Jurnal Mentari [serial on the internet]. 2011 [cited 2015 Des 23];14 (2). Available from: http://ejournal.unmuha.ac.id/index. $\mathrm{php} / \mathrm{mentari} /$ article/view/92

23. Herman. Pengaruh latihan terhadap fungsi otot dan pernapasan. Jurnal ILARA. 2010;1:27-29.

24. Price SA, Wilson LM. Patofisiologi: konsep klinis proses- proses penyakit (Edisi ke-6). Jakarta: EGC; 2012. h. 768-9. 